Journal of Research in Interprofessional

Practice and

Education

Vol. 3.3

February, 2014

\title{
What Does Collaborative Practice Mean within Mental Healthcare? A Qualitative Study Exploring Understandings and Proposing a Definition
}

\author{
Gabrielle Margaret Jones, BHSc \& \\ Toni Delany, BSSci, BHSci (Hons), PhD
}

\begin{abstract}
Background: Despite frequent appearances in service documents, the concept of collaborative practice is ill defined in mental health practice. The purposes of this pilot study were to gain insight into professionals' conceptual and practical understandings of collaborative mental health practice (CMHP), to use these insights to develop a proposed definition, and to inform the development of a collaborative practice assessment tool.

Methods and findings: This pilot study involved semi-structured interviews with four mental health professionals who have knowledge of a service model that endorses collaborative practice as a service principle. Thematic analysis of interview data revealed the importance of contextualized collaborative practice, a shared belief in the importance of equalized communication with clients, and concerns about the impacts of structural disincentives on collaborative practice. Using Habermas' theory of communicative action, the findings were applied to develop a proposed definition of CMHP. The main limitations of the study relate to small sample size; however, efforts have been expended to ensure rich data were collected from all participants.

Conclusion: These findings illustrate the importance of context-sensitive team formation and shared philosophical understandings regarding collaborative practice, which both provide a foundation for CMHP to improve client outcomes. Further research is required to build upon the proposed definition of CMHP, as well as the assessment tool that is suggested within the article.
\end{abstract}

Keywords: Qualitative; Collaborative practice; Mental health

\section{Introduction}

Throughout the world, health systems are under strain due to a complexity of factors, including heightened community and patient expectations, shortages of health professionals, an aging workforce, and poor communication [1-3]. Mental health services contend with these, as well as the additional challenges of stigma and client disempowerment, within a hierarchical and medically dominated structure [4]. Mental health service delivery can also be hindered by underdeveloped cross-sectoral and co-ordinated responses $[2,5]$. The resultant tensions contribute to compromised patient safety, which has been linked to preventable death and disability [6].

A widely held perception among healthcare stakeholders, enshrined in numerous policy and practice documents, is that collaborative practice is beneficial to enhancing the co-ordination of responses, which, in turn, improves client care and health outcomes [7-10]. The World Health Organization (WHO) [11] offers one definition of collaborative practice as "clinical and non-clinical health-related practice in healthcare occur[ing] when multiple workers from different professional back-

Journal of Research Education (JRIPE)

Vol. 3.3

(C) 2014

Corresponding author: Gabby Jones. Email: Gabby.Jones@healthi 's.sa.gov.auui' 
2

Defining Mental Health Collaborative Practice

Jones

\& Delany

Journal of Research in Interprofessional Practice and Education

Vol. 3.3

February, 2014 grounds provide comprehensive services by working with patients, their families, carers and communities to deliver the highest quality of care across settings" [p. 7].

However, this definition is widely contested and perceived to be inadequate when contextualized to mental health practice [4]. The definition fails to encapsulate the complex, broad-spanning processes involved in collaborative practice, including articulating its componentry, implementation methodology, or measures [12]. It also omits various key stakeholders, is not contextualized, and does not define effectiveness in relation to mental health or any other health outcomes $[13,14]$. These are vital points that are central to collaborative mental health practice (CMHP). The lack of a comprehensive, contextually appropriate definition reinforces the need to establish an agreed definition that will enable research to progress and support the work of those engaging in CMHP.

It is not surprising that contextualized definitions of collaborative practice are in their infancy, when collaborative practice itself is still a contested area. Illustrating the lack of clarity concerning a definition of collaborative practice, McDonald, Davies, Cununingand, and Harris [15] found that the term "care co-ordination" is used interchangeably with approximately 40 definitions of similar practice (including collaborative practice). Similarly, Nolte and McKee [16] found that a variety of terms are used to describe similar practices, including, most notably, collaborative practice, co-ordinated care, and patient-centred care. Further confusing the matter is that these same words can have different definitions within different fields [17].

Other issues that arise from the absence of a clear definition of collaborative practice include the lack of valid and reliable measurement scales, its introduction is often manager/policy driven (versus an inclusive team, organizational, and client approach), and, that unique settings can limit transferability [17,18]. Conversely, studies have also found that health professionals have a general understanding of collaborative practice, believe it has value, and strive to promote its use, although they experience difficulty translating it into practice [19, 20]. Oandasan et al. [9] also highlight that effective collaborative practice can be hindered by government policy and structures. WHO [11] recommends that these issues be addressed through improving normalization and uptake when promoting collaborative practice within individual health services and across sectors supported by policy and education. This may be viewed as somewhat simplistic if collaborative practice is seen as existing within a complex adaptive system that considers the challenges of sustainable change [21].

Despite its widespread introduction, collaborative practice research is also rarely informed by theory [20]. Some examples exist in the literature, such as Gask et al.'s [8] use of the "Normalisation Process Model" and Nutbeam and Harris' [22] "Diffusion of Innovation." These provide useful insight into components of collaborative practice implementation but fall short of a global theoretical paradigm $[20,23]$. The current pilot study addresses this by applying Habermasian theory as a theoretical basis for generating a contextually specific and inclusive definition of collaborative practice in the area of mental health. 
3

Defining Mental Health Collaborative Practice

Jones

\& Delany
Journal of Research in Interprofessional Practice and Education

Vol. 3.3

February, 2014

\section{The theory of communicative action}

Habermas' theory of communicative action explains how communication creates and drives the possibility for different types of actions [24,25]. He sees the most positive process and outcome of communication as communicative action, which is defined as action oriented toward reaching a shared understanding. This type of communication is also a core tenet of collaborative practice. Habermas identified other types of communications that lead to less positive outcomes [26]. Instrumental action is a critical point that, depending on the motivation, leads to either communicative or strategic action [24]. Communicative action is fundamentally opposed to strategic action, where strategic action leads to organizations or individuals directing, manipulating, or controlling situations [27]. Conversely, communicative action seeks to direct and co-ordinate a group through egalitarian, receptive, and debatable communication that is oriented toward reaching understanding [as cited in 27]. Although Habermas believes that communicative action is utopian, mental health clients are particularly susceptible to being exposed to strategic action [24], due to their vulnerability and marginalization. The particular challenges that this client group faces highlight the need for a focused and specialized conceptualization of collaborative practice that is relevant to the area of mental health.

Drawing on the theory of communicative action, this explorative pilot study examined health professionals theoretical understandings and philosophical beliefs relating to collaborative practice in a mental health context. The aim of the research was to inform implementation of collaborative practice within the Improving Access to Psychological Therapies at Flinders service model (IAPT@Flinders) and ultimately to improve client outcomes [10]. Through applying the theory of communicative action, the following research questions were explored:

1. What do mental health professionals understand collaborative practice to mean within the context of both mental health care and their professional experience?

2. Are there any differences between the World Health Organization's definition of collaborative practice and mental health professionals' understanding of collaborative mental health practice?

3. How can collaborative practice be most appropriately defined in the context of mental health care?

\section{Methods}

A hermeneutic approach was applied during the research [28]. This approach enabled the collection and interpretation of data from health professionals who are part of the mental health treatment community. It also encouraged the researcher to apply the knowledge that was collected from members of this community by developing a working definition and assessment tool [29]. During the research, interviews were undertaken to collect information about mental health professionals' experiences and views of collaborative practice in the mental health context of the IAPT@Flinders. Researcher observations were also recorded in a journal and these were analyzed as data. Data analysis and collection occurred concurrently, which 


\section{JRIPE}

4

Defining Mental Health Collaborative Practice

Jones

\& Delany

\section{Journal of Research in Interprofessional Practice and Education}

supported the rigour of the research by allowing for continuous reflection [30] on the relevance of the interview questions and observation foci to the emerging data.

\section{Participants}

Four health professionals who had intimate knowledge of the conceptual framework of IAPT@Flinders were selected for this exploratory study. Their de-identified details are summarized in Table 1. Due to the specific focus of this pilot study, clients were not included.

Table 1: Participant table

\begin{tabular}{|l|c|c|l|c|l|}
\hline Pseudonym & Age & Gender & Profession & Years of practice & Role \\
\hline John & 44 & M & Social Worker & 20 & Drug and Alcohol Services \\
\hline Tom & 38 & M & Psychiatrist & 15 & Clinical Director \\
\hline Janice & 49 & F & $\begin{array}{l}\text { Consultant Nurse } \\
\text { Psychotherapist }\end{array}$ & 31 & $\begin{array}{l}\text { Psychotherapist/Lecturer/Acting Team } \\
\text { Leader }\end{array}$ \\
\hline Don & 47 & M & $\begin{array}{l}\text { Mental Health } \\
\text { Nurse }\end{array}$ & 16 & ED Mental Health Nurse \\
\hline
\end{tabular}

Interviews

Semi-structured interviews were conducted during April and May 2011 and recorded using a digital recorder. The purpose of the study and the interview questions were identified in an introductory letter and information sheet. The interviews were time generous (average duration 1.5 hours), in-depth, and detailed, which proved effective in generating rich data. Deep probing during the interviews ensured comprehensive and accurate understanding, thereby further supporting rigour [30]. In addition, participants were offered the opportunity to review the transcript of their interview and add additional detail to their answers. This process resulted in the further collection of data beyond the interviews, which added richness.

\section{Interview Questions}

The following questions were asked:

1. What do you see as some of the key features of a person who is mentally unwell?

2. What does it mean to you to be a (insert profession)?

3. In an ideal world, what would a mental health care team look like?

4. How do you define collaborative practice?

5. What positives are associated with working in a collaborative mental health care team?

6. What negatives are associated with working in such a team?

7. How do you think communication and care might be affected by working within a collaborative mental health team? 
5

Defining Mental Health Collaborative Practice

Jones

\& Delany
Journal of Research in Interprofessional Practice and Education

Vol. 3.3

February, 2014

\section{Observations}

Additional data were collected via the interviewer's journal, which included researchers' observations. Collection of this information assisted in refining questions based on perceived level of engagement and comfort of interviewees, and in exploring personal stories. All observation notes and other research documents included codes rather than participant names to protect the identity of participants. Pseudonyms are included throughout this article.

\section{Data analysis}

The transcripts and journal were examined through preliminary data analysis after each interview to refine and refocus interview questions and probing. Next, thematic analysis on transcribed data was conducted by reading, annotating, and rereading the data to identify key themes. Keyword searches were used during the early analysis period to identify concept repetition [31]. Collaborative coding and discussion of the data was also undertaken to ensure rigour [30].

During analysis of the data the theory of communicative action was applied because it provides a transferable test and salient lens through which to consider collaborative practice in service development. Applying this theory to the test case of the IAPT@Flinders model allowed for assessment of the strengths and weaknesses of relationships where collaborative practice has the potential to occur. Following thematic data analysis and application of the theory, individual themes were applied to the various tests and rules within the schema (Diagram 1). For instance, in regard to research question 1-What do mental health professionals understand collaborative practice to mean within the context of both mental health care and their professional experience? - the theme that emerged from this question was of "inclusivity and respect for the people with whom they interact as part of their work." After identifying this theme, the relevant data were applied to the schema to assess if the worldviews expressed would likely result in communicative action. This practical application of the schema is discussed in further detail in the results section. Use of Habermas' [26] theory during data analysis enabled examination of how communication influences service provision, the workplace, and team development. Synthesizing and collating the understandings outlined in the results and discussion subsequently informed the proposed definition and evaluation tool of CMHP. Additionally, the IAPT@Flinders model was used as a test case, as collaborative practice is stated as a key service principle. Diagram 1, "The schema of aspects of Habermas' theory of communicative action" (the schema), forms the basis of a proposed CMHP evaluation tool.

\section{Results and discussion}

Overall, the findings revealed that participants believed that collaborative practice features in their professional practice paradigms. During the analysis, the findings were grouped into four broad themes to explain the information that emerged from participants' experiences. These have been collated into Table 2 to illustrate inter- 


\section{Diagram 1: Schema of aspects of Habermas' theory of communicative action (the schema)}

\begin{tabular}{|c|c|c|c|c|c|c|}
\hline $\begin{array}{l}\text { Classification } \\
\text { Criteria }\end{array}$ & $\begin{array}{l}\text { Life world } \\
\text { (column 1) }\end{array}$ & $\begin{array}{c}\text { Validity } \\
\text { claims } \\
\text { (column 2) }\end{array}$ & $\begin{array}{l}\text { Principles } \\
\text { (column 3) }\end{array}$ & \multirow{6}{*}{ 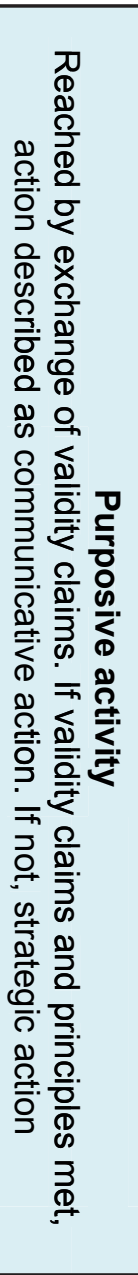 } & \multirow{3}{*}{ Marginalisation } & \multirow{3}{*}{$\begin{array}{c}\text { Strategic Action } \\
\text { Communication } \\
\text { oriented to gain control, } \\
\text { manipulate or dominate } \\
\text { Example: Structured } \\
\text { inequality, bureaucracy } \\
\text { in healthcare systems }\end{array}$} \\
\hline $\begin{array}{l}\text { Participant } \\
\text { Communication }\end{array}$ & $\begin{array}{l}\text { Communication exists } \\
\text { within three life worlds: } \\
\text { Humanity has } \\
\text { predisposition for } \\
\text { rationality }\end{array}$ & $\begin{array}{l}\text { Using power of } \\
\text { reason, test } \\
\text { within each life } \\
\text { world to } \\
\text { classify } \\
\text { resultant action }\end{array}$ & $\begin{array}{c}\text { Applied to } \\
\text { validity claims, } \\
\text { presumed act } \\
\text { is } \\
\text { comprehensible }\end{array}$ & & & \\
\hline \multirow{3}{*}{ Hospital } & \multirow{4}{*}{$\begin{array}{l}\text { Components of } \\
\text { consumers' life world: } \\
\text { (1) Objective } \\
\text { Concerned with } \\
\text { practical/cultural } \\
\text { - Theoretical interaction } \\
\text { (2) } \frac{\text { Intersubjective/ }}{\text { Normative }} \\
\text { Concerned with social } \\
\text {-Practical interaction } \\
\text { (3) Subjective/inner } \\
\text { Concerned with inner } \\
\text { self } \\
\text {-Personality interaction }\end{array}$} & \multirow[b]{2}{*}{ Truth of claim } & \multirow[b]{2}{*}{$\begin{array}{c}\text { Right to } \\
\text { participate and } \\
\text { disagree in } \\
\text { free and open } \\
\text { discourse }\end{array}$} & & & \\
\hline & & & & & $\begin{array}{l}\text { Instrumental } \\
\text { action } \\
\text { Objective } \\
\text { scientific or } \\
\text { procedural truth. } \\
\text { Subordinate (or a } \\
\text { tool) to either } \\
\text { communicative or } \\
\text { strategic action } \\
\end{array}$ & \\
\hline & & $\begin{array}{l}\text { Conduct/ } \\
\text { rightness }\end{array}$ & $\begin{array}{l}\text { Motivation } \\
\text { for } \\
\text { consensus }\end{array}$ & & & \multirow{2}{*}{$\begin{array}{l}\text { Communicative Action } \\
\text { Communication } \\
\text { oriented toward } \\
\text { reaching consensus } \\
\text { through open and } \\
\text { receptive debate. } \\
\text { Example: } \\
\text { IAPT@Flinders } \\
\text { Collaborative Practice } \\
\text { Team }\end{array}$} \\
\hline $\begin{array}{l}\text { IAPT@Flinders } \\
\text { Collaborative } \\
\text { Practice Team }\end{array}$ & & $\begin{array}{l}\text { Sincerity/ } \\
\text { authenticity }\end{array}$ & $\begin{array}{l}\text { Awareness of } \\
\text { consonance of } \\
\text { thoughts, } \\
\text { feelings, } \\
\text { actions to self, } \\
\text { society and } \\
\text { environment }\end{array}$ & & lared & \\
\hline
\end{tabular}

Note: Kubacki 1994 [25]; Habermas 1984b [26]; Brand 1990 [27] 
Table 2: Thematic data analysis

\begin{tabular}{|c|c|c|c|c|c|c|c|}
\hline A. Lived experience & B. Practice & C. Marginalization & D. Collaborative approach & E. Barriers & F. Policy disincentive & G. Power & H. Contextualization \\
\hline $\begin{array}{l}\text { Dynamic concept of } \\
\text { emotional instability }\end{array}$ & $\begin{array}{l}\text { People/personal; con- } \\
\text { nected, passion, joys, } \\
\text { achieve, fantastic, great } \\
\text { opportunity, holistic, col- } \\
\text { lective spirit }\end{array}$ & $\begin{array}{l}\text { Values of human dignity } \\
\text { and self-worth, working } \\
\text { for the underdog }\end{array}$ & $\begin{array}{l}\text { Common approach and } \\
\text { core vision with common } \\
\text { goal and philosophies }\end{array}$ & $\begin{array}{l}\text { External threats; jeal- } \\
\text { ousy and rivalry }\end{array}$ & $\begin{array}{l}\text { Client fitting into the system, } \\
\text { focused on system }\end{array}$ & $\begin{array}{l}\text { Historical foundation of } \\
\text { medical model, medi- } \\
\text { cine as hierarchy }\end{array}$ & Mechanisms and agreements \\
\hline $\begin{array}{l}\text { Not coping or function- } \\
\text { ing }\end{array}$ & $\begin{array}{l}\text { Unjust and complicated } \\
\text { world }\end{array}$ & $\begin{array}{l}\text { Warden days, "The } \\
\text { Backwards", a bin }\end{array}$ & Consumer at centre & $\begin{array}{l}\text { Different } \\
\text { language/approaches } \\
\text { of different professions }\end{array}$ & $\begin{array}{l}\text { Medicare referral through GP, } \\
\text { no funding incentives }\end{array}$ & $\begin{array}{l}\text { Professional hierarchies, } \\
\text { prejudices, rivalries }\end{array}$ & $\begin{array}{l}\text { Government and non-govern- } \\
\text { ment working together }\end{array}$ \\
\hline $\begin{array}{l}\text { Broader systems/psy- } \\
\text { chosocial view }\end{array}$ & $\begin{array}{l}\text { Clients'journies, practically } \\
\text { oriented, working with } \\
\text { them, patient-centred }\end{array}$ & $\begin{array}{l}\text { Safe and away from } \\
\text { society }\end{array}$ & Communication & Insular & $\begin{array}{l}\text { Set up to fail, fall through gaps, } \\
\text { reliance on system }\end{array}$ & $\begin{array}{l}\text { Medicalization of symp- } \\
\text { toms }\end{array}$ & $\begin{array}{l}\text { Culture has role in shaping } \\
\text { mental unwellness }\end{array}$ \\
\hline $\begin{array}{l}\text { Environmental buffers } \\
\text { or reinforcers }\end{array}$ & $\begin{array}{l}\text { Consumer rights, patient } \\
\text { as expert, respected }\end{array}$ & $\begin{array}{l}\text { Belief if mad, they } \\
\text { will harm somebody; } \\
\text { portrayals of madness } \\
\text { on TV }\end{array}$ & $\begin{array}{l}\text { Opportunities for learning } \\
\text { and sharing experience }\end{array}$ & $\begin{array}{l}\text { Miscommunication, } \\
\text { duplication, confusion }\end{array}$ & $\begin{array}{l}\text { Waiting periods, under resourced, } \\
\text { impersonal, uncoordinated, } \\
\text { assumptions, access, siloed } \\
\text { approach, risk focus }\end{array}$ & $\begin{array}{l}\text { Hospitals over reliant } \\
\text { on hierarchy }\end{array}$ & Distinct construction of team \\
\hline $\begin{array}{l}\text { Complex grey area } \\
\text { with philosophical } \\
\text { foundations }\end{array}$ & $\begin{array}{l}\text { Consumers as individuals, } \\
\text { helping, shared responsi- } \\
\text { bility and social emphasis }\end{array}$ & $\begin{array}{l}\text { Stigma around today, } \\
\text { shoe box and label peo- } \\
\text { ple }\end{array}$ & $\begin{array}{l}\text { Culture: Working well } \\
\text { together, openness, clarity, } \\
\text { personality, sharing, excel- } \\
\text { lence, respect }\end{array}$ & Difficult to coordinate & $\begin{array}{l}\text { Medical model of illness limits } \\
\text { funding to medically focused/ } \\
\text { referral system, medicalized view } \\
\text { that excludes consumer }\end{array}$ & $\begin{array}{l}\text { Care around medica- } \\
\text { tion. Social work seen } \\
\text { as an add on }\end{array}$ & $\begin{array}{l}\text { Mixed private, public, } \\
\text { organizational interagency } \\
\text { work }\end{array}$ \\
\hline Sociological & Part of me & $\begin{array}{l}\text { Current system } \\
\text { disempowering through } \\
\text { reliance on professional } \\
\text { help }\end{array}$ & $\begin{array}{l}\text { Understanding and appre- } \\
\text { ciating team's experience, } \\
\text { expertise, perspectives, } \\
\text { opinion, knowledge }\end{array}$ & Conflict & $\begin{array}{l}\text { No mechanisms for team based } \\
\text { work, finish an episode which } \\
\text { statically closes - around closure } \\
\text { and opening }\end{array}$ & $\begin{array}{l}\text { World is constructed in } \\
\text { a hierarchical way }\end{array}$ & Local nuances \\
\hline $\begin{array}{l}\text { Individual perspective } \\
\text { and world view }\end{array}$ & $\begin{array}{l}\text { Rapport and good thera- } \\
\text { peutic and interpersonal } \\
\text { relationships }\end{array}$ & $\begin{array}{l}\text { Professionalization of } \\
\text { distress }\end{array}$ & Rare and precious thing & Become dysfunctional & $\begin{array}{l}\text { Pressures of the system, restraints } \\
\text { of time, no checking mechanism }\end{array}$ & Disrespect & \\
\hline $\begin{array}{l}\text { Impacting on work, } \\
\text { social relationships; } \\
\text { self-harming }\end{array}$ & Family feel & $\begin{array}{l}\text { Weakness and personal } \\
\text { responsibility }\end{array}$ & Collectivism & $\begin{array}{l}\text { Professional } \\
\text { demarcation }\end{array}$ & Culture, politics and power & & \\
\hline
\end{tabular}


Defining Mental Health Collaborative Practice

Jones

\& Delany
Journal of Research in Interprofessional Practice and Education

Vol. 3.3

February, 2014
Journal of Research in Interprofessional Practice and Education

connected, contrasting, and nuanced insights into health professionals' views of collaborative practice within a unique Australian mental health context. Each theme also contributes to addressing the stated research questions.

\section{Contextualized collaborative practice}

In the context of discussing IAPT@Flinders, interviewed professionals expressed views of collaborative practice which resonate with three of the life worlds (schema column one) that provide the necessary conditions for communicative action to occur.

Objective: Application of collaborative practice is recommended as best practice by prominent authorities, thereby promoting the credibility of the model $[11,32]$. One participant, John, expresses his practical and cultural endorsement:

This is a really interesting model that, if it's successful, could change the way this emergency department works; [it] could change the way emergency departments work across the state and potentially across the country. Potentially, if it's really effective and innovative and successful, who knows where it will go? That's exciting.

Intersubjective: The common usage of the concept of collaborative practice facilitates and encourages intersubjective understanding and acceptability between key players. This inclusion within the IAPT@Flinders service framework will help to forge a shared understanding among interviewed health professionals $[1,10]$. Tom discusses how this social cohesion could evolve in practice:

Key ingredients are: a shared vision about why these people are aggregating as a team, shared ideologies, shared working frame of reference that is client centred, respect for each other's abilities, a learning environment where you're trying to learn from each other.

Subjective: The worldview expressed by interviewed health professionals of equality within their relationships and interactions with clients and colleagues supports personal alignment with collaborative practice [24]. Don expresses this personal professional communication as:

We all have an opinion and knowledge and experience that we can bring to the table.

Assessing whether the validity claims (schema column 2) have been met following the introduction of collaborative practice to IAPT@Flinders requires understanding whether they are likely to satisfy criticizable claims within the various life worlds of key players. This is possible when speech appears understandable and when dialogue is "true," socially acceptable, and genuine [24].

Schema column 3 identifies principles of communication. Interviewed health professionals' views adhered to the principles of free participation and ability to disagree without consequence, the desire to reach consensus with minimal constraints of power differentials, and acceptance by not only those who agree with the action 
Defining Mental Health Collaborative Practice

Jones \& Delany
Journal of Research in Interprofessional Practice and Education

Vol. 3.3

February, 2014

\section{Journal of Research in Interprofessional Practice and Education}

but also those who may be affected [33]. Having successfully passed these tests, the resultant action of introducing collaborative practice at IAPT@Flinders is predicted to fulfill the requirements of communicative action. The next section will explore and expand these claims.

\section{Key players in the Collaborative Practice Team with client as integral} Interviewed health professionals expressed a worldview of inclusivity and respect for the people with whom they interact as part of their work. This holistic care paradigm was defined as featuring rapport, communication, respect, and concern for the psychosocial, and it correlates with several of the proposed key drivers informing collaborative practice as well as being compliant with the test of communicative action [6]. With a foundation built on teamwork, Janice expressed her view on team structures and formation, demonstrating her desire to achieve "accomplishments on which cooperative processes ... are based [that] represent the mechanism for coordination" [24]. Expanding on this understanding, she believes in:

getting people who are really keen and dedicated and actually listening, sharing, discussing, exploring, [and] respecting everybody's expertise. That team would probably be a collaborative, multidisciplinary team, and it has to be that, because we are all there, we're all in it together. (Janice)

Interviewed health professionals also expressed an understanding of collaborative practice that included attributes of egalitarian, multidisciplinary teamwork; shared philosophies; and open communication with a driving motivation of "client as integral" $[17,34]$. Janice expressed this as:

Nobody runs ahead, nobody lags behind; you're working side by side as a team toward the same goal. That sometimes is an art in itself. Keeping everybody side by side.

This study found that clients were viewed as a central part of the team and an essential component of collaborative practice:

I would also bring in that collaborative practice should include the patient. (Don)

This motivation to work in a collaborative manner was reflected in the findings relating to clinical approaches that were open, empathic, and demonstrate a shared understanding of practice, centred in clients' lived experience and client centrality to collaborative practice:

Having an agreed goal with the client and working with the client on their issues and not 'on' the client [is] around collaboration with the client. It's my way of looking at it. It's the client's journey. I might be walking with them on this pathway, but it's their journey. It's their life. (John) 
Defining Mental Health Collaborative Practice

Jones

\& Delany
Journal of Research in Interprofessional Practice and Education

Vol. 3.3

February, 2014

\section{Journal of Research in Interprofessional Practice and Education}

These aspects of collaborative practice can be assessed by applying the schema (Diagram 1) to determine if the criteria for communicative action have been met. This is based on satisfying basic validity claims and principles within each of the health professionals' life worlds and is demonstrated through key aspects of:

- Promoting truth of claim and sincerity/authenticity; motivation for consensus when working toward clients' goals:

It's about the client as the starting point.... Collaboration with the client that means transferring ownership, power, autonomy, personal decision making onto the client and being receptive to their needs and their wishes. (Tom)

- Conduct/rightness and right to participate; supporting mutually respectful and open teamwork with client as integral:

The client being at the centre of this collaborative care team and where the team meets maybe ideally the client is part of that process. (Tom)

It's the lens through which I see the world as a professional and in my life, values of human dignity and self-worth [make me] feel connected. (John)

- Awareness of environment that recognizes psychosocial challenges and focus on dissonant mental states which acknowledges a truth of claim and right to participate in free and open discussion [27]:

Just to be able to communicate in a safe environment. It comes back to that respect and you can say [anything] and the person would say "that's fine." (Janice)

These findings somewhat align with and support the WHO's (2010) definition; however, they contrast with the body of literature that identifies collaborative practice as a professional tool rather than as co-ordinated care with client as central $[9,14,20]$. Tom discusses his experience of this broader conceptualization:

So [in the] catchment area: client rights, client participation, care planning, clients at governance meetings, clients everywhere. [They were] role models for managers that focus on population health outcomes. It was clear we were here to service our community.

\section{Contextualization, marginalization, and policy disincentives}

This study supports existing literature that highlights the importance of collaborative practice being contextualized and embedded within workplace culture and practice paradigms [1]. This can be tested using the schema (Diagram 1) to define attempts to normalize collaborative practice within IAPT@Flinders which have been made through open, respectful, and professional communication and motivated toward consensus. 
Defining Mental Health Collaborative Practice

Jones \& Delany

A common theme identified in this study, however, is the view that a pervasive negative influence prevails due to policy disincentives within the Australian healthcare sector. This can result in a system geared for strategic action where communication is structured toward gaining and maintaining control through policy and structures. Tom's frustrations with barriers and system boundaries [8] that perpetuate strategic discourse are demonstrated in his views of the

siloed approach [that fosters] possible prejudices and rivalries of different models [with an] over reliance on hierarchy within a system that has no mechanism, funding, or incentive for team-based work. (Tom)

Oandasan et al. [9] support the view that a major barrier to effective collaborative practice is marginalization and service structures. The perceived lack of structural financial incentive for cross-disciplinary or cross-sectorial collaboration directly reflects strategic action through this structured inequality of bureaucracy on which the Australian health system is built $[9,11]$.

Don shared his views of tensions in an Australian medically dominated healthcare system and how marginalization can occur even in collaborative environments:

We had one of the head surgeons in the hospital come to Prof with a problem. Prof saw me walk past and called me in. He said, "Don, what do you think about this problem?" and we talked about it. And then afterward the surgeon asked Prof, "Why did you call the nurse in to see you?" because it is something he would never consider doing. And Prof said, "Well, this is just what we do." (Don)

This type of marginalization is counterintuitive to collaborative practice's aspiration of working co-operatively and respectfully $[11,34]$. It also can be interpreted as strategic communication that seeks to gain control or dominate.

Highlighting the need to contextualize collaborative practice to ensure its relevance and appropriateness, Suter [19] found that health professionals are uncertain about how to implement collaborative practice. This is unsurprising considering the poor understandings surrounding its definition and transference into practice:

I know X and their group claims to do collaborative care, but I am yet to see that in true practice. That's why I get confused about this collaborative practice ... I've seen all the ... training and courses.... That's what I'm puzzled about. I still don't understand why I don't see it. (Tom)

It is probable that many organizations attempting to introduce collaborative practice will have limited success because of their inability to clearly define its objec-

Journal of Research in Interprofessional Practice and Education

Vol. 3.3

February, 2014 tives or demonstrate its success. According to the theory of communicative action, uncertainties around implementation compromise the principles of motivation for consensus and undermine the right to participate in open discourse. Additionally, lack of clarity regarding expectations of collaborative practice will raise questions about the sincerity and authenticity of its purpose. 
Defining Mental Health Collaborative Practice

Jones \& Delany

Journal of Research in Interprofessional Practice and Education

Vol. 3.3

February, 2014

\section{Journal of Research in Interprofessional Practice and Education}

\section{Power and hierarchies}

Habermas was concerned with the development of administrative "systems," such as the healthcare industry, that are impacted by power and financial pressure and may be managed by strategic actions [25]. Such institutions assist the "internal colonisation of the life world" [35, p. 225] by increasingly imposing on the private domain. This type of system intrusion into the lives of mentally ill clients is consistent with several themes found in this study, in particular, marginalization and power. This is also particularly relevant to the research questions in understanding how collaborative practice can be defined in the context of mental healthcare.

An objective of the IAPT@Flinders' collaborative practice service principle is to improve mental health outcomes by providing links between medical health systems and service users. The way communication is performed is the responsibility of the collaborative practice team that is also under institutional governance. This study found themes of power hierarchies, barriers to free participation, and a lack of consensus decision making that may fail the validity claims and principles to qualify for communicative action [27]. This is particularly important to IAPT@Flinders, as mental health traditionally reflects notions of disempowerment and control created through strategic action [27]. John, describing the contrast between his vision of the IAPT@Flinders service and his then current workplace:

be very beneficial under the new model [where we have the] opportunity and are encouraged to think really clearly [about how] people see their role. There is that team and you are co-ordinating care on an individual basis; you can be very clear about the role and what each is doing, whereas at $\mathrm{X}$ we have the case management system, but it's more that the client fits into the system. (John)

The medical model was generally found to represent a significant barrier. Janice articulates the entrenched nature of this as:

People who are up there, hopefully nearly retiring soon, are the ones that are maintaining that culture. (Janice)

This view is consistent with the findings of previous research which indicate that manager- and policy-driven initiatives are less effective than holistic and co-operative clinician- or patient-driven quality improvement strategies [18]. Furthermore, it is a salient example of how strategic action may occur when people are not actively participating. These findings again highlight the problems associated with the lack of a standard definition, which limits the transferability of results and research into the key components that comprise collaborative practice $[13,17]$.

Based on the findings of this research, a new, contextually driven definition of CMHP practice is proposed:

Collaborative mental health practice is a code of practice enacted by multidisciplinary workers to establish an accessible communication and care framework with clients, their families, carers, and other key stakeholders whose purpose is to facilitate consensus based on egal- 
JRIPE

13

Defining Mental Health Collaborative Practice

Jones

\& Delany itarian principles of inclusivity, respect, and equality in order to provide quality holistic care.

\section{Limitations}

This pilot study has some limitations. At the time it was undertaken, IAPT@Flinders was yet to be operationalized, so practical concept analysis was not possible. In addition, the small sample size may not have provided sufficient breadth to fully explore the complexity of collaborative practice. However, this pilot provides a solid basis from which further exploration of the identified themes can be undertaken.

\section{Conclusion}

This study suggests that the unique service requirements of mental health clients require a judicious definition of CMHP to be developed. Designing services that are consistent with health professionals' general underlying philosophies of collaborative engagement are likely to be more effective when implementing collaborative practice. It is recommended that where service has a principle of collaborative practice, the worldview of applicants be assessed for consistency with the concept during recruitment. Furthermore, the importance of these factors should be recognized in team training and development. The schema of Habermas' communicative action is recommended as a useful tool to assess the quality of communication, which is the essence of collaborative practice. This tool allows identification of potential breakdowns and barriers that are critical factors to successful collaborative practice. Based on the findings of this pilot study, the proposed definition and conceptual assessment tool provides a basis for further research to build upon and modify in order to develop one that encapsulates the nuances and potential impacts of CMHP.

\section{Abbreviations}

CMHP: Collaborative Mental Health Practice

WHO: World Health Organization

IAPT@Flinders: Improving Access to Psychological Therapies at Flinders service model

\section{References}

1. Learning and Teaching for Interprofessional Practice. (2009). Interprofessional health education in

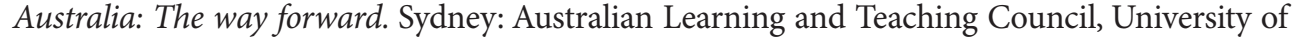
Sydney and University of Technology. URL:!http://wwwwaippen.net/docs/LTIPP [ [March 14, 2011].

2. Knapp, M., Funk, M., Curran, C., Prince, M., Grigg, M., \& McDaid, D. (2006). Economic barriers to better mental health practice and policy. Health Policy and Planning, 21(3), 157-170.

3. Allen, D., Gillen, E., \& Rixson, L. (2009). Systematic review of the effectiveness of integrated care pathways: What works, for whom, in which circumstances? International Journal of EvidenceBased Healthcare, 7(2), 61-74.

Journal of Research in Interprofessional Practice and Education

4. Thistlethwaite, J., Jackson, A., \& Moran, M. (2013). Interprofessional collaborative practice: A deconstruction. Journal of Interprofessional Care, 27(1), 50-56.

5. Henderson, J. (2008). Biological psychiatry and changing ideas about 'mental health prevention' in Australian psychiatry: Risk and individualism. Health Sociology Review, 17(1), 4-17. 
14

Defining Mental Health Collaborative Practice

\section{Jones}

\& Delany
Journal of Research in Interprofessional Practice and Education

Vol. 3.3

February, 2014
6. Doessel, D., Williams, R., \& Whiteford, H. (2010). The trend in mental health-related mortality rates in Australia 1916-2004: Implications for policy. Australia and New Zealand Health Policy, 7(3), 1-10.

7. Reeves, S., Goldman, J., \& Oandasan, I. (2007). Key factors in planning and implementing interprofessional education in health care settings. Journal of Allied Health, 36(4), 231.

8. Gask, L., Bower, P., Lovell, K., Escott, D., Archer, J., Gilbody, S., Lankshear, A.J., Simpson, A.E., \& Richards, D.A. (2010). What work has to be done to implement collaborative care for depression? Process evaluation of a trial utilizing the Normalization Process Model. Implementation Science, 5(15), 1-15.

9. Oandasan, I., Baker, R., Baker, K., Bosco, C., D’Amour, D., Jones, L., Kimpton, S., Lemieux-Charles, L., Nasmith, L., San Martin Rodriguez, L., Tepper, J., \& Way, D. (2006). Teamwork in health care:

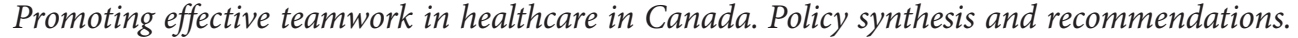

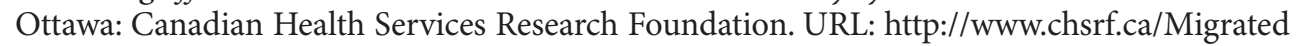
i/PDF/teamwork-synthesis-report_e.pdf; [May 20, 2011].

10. Wood, V. (2009). Road to collaboration: Developing an interprofessional competency framework. Journal of Interprofessional Care, 23(6), 621-629.

11. Health Professions Network Nursing and Midwifery Office. (2010). Framework for action on inter-

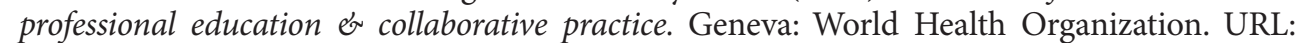
'http://www.who.int/hrh/nursing midwifery/en/'[March 6, 2011].

12. Reeves, S., Goldman, J., Gilbert, J., Tepper, J., Silver, I., Suter, E., \& Zwarentein, M. (2011). A scoping review to improve conceptual clarity of interprofessional interventions. Journal of Interprofessional Care, 25(3), 167-174.

13. Goldman, J., Zwarenstein, M., Bhattacharyya, O., \& Reeves, S. (2009). Improving the clarity of the interprofessional field: Implications for research and continuing interprofessional education. Journal of Continuing Education in the Health Professions, 29(3), 151-156.

14. Reeves, S., Zwarenstein, M., Goldman, J., Barr, H., Freeth, D., et al. (2008). Interprofessional education: Effects on professional practice and health care outcomes. Cochrane Database of Systematic Reviews, 1(1), 1-22.

15. McDonald, J., Davies, G.P., Cununingand, J., \& Harris, M.F. (2007). What can the experiences of primary care organisations in England, Scotland and New Zealand suggest about the potential role of divisions of general practice and primary care networks/partnerships in addressing Australian challenges? Australian Journal of Primary Health, 13(2), 46-55.

16. Nolte, E., \& McKee, M. (2008). Integration and chronic care: A review. In Nolte, E., \& McKee, M. (Eds.), Caring for people with chronic conditions: A health system perspective. (pp. 64-91). Berkshire, UK: Open University Press.

17. Zwarenstein, M., Goldman, J., \& Reeves, S. (2009). Interprofessional collaboration: Effects of practice-based interventions on professional practice and healthcare outcomes (Review). Cochrane Database of Systematic Reviews, Issue 3. Art. No.: CD000072.

18. Scott, I. (2009). What are the most effective strategies for improving quality and safety of health care? Internal Medicine Journal, 39(6), 389-400.

19. Suter, E. (2009). Role understanding and effective communication as core competencies for collaborative practice. Journal of Interprofessional Care, 23(1), 41-51.

20. Zwarenstein, M., \& Reeves, S. (2006). Knowledge translation and interprofessional collaboration: Where the rubber of evidence-based care hits the road of teamwork. Journal of Continuing Education in the Health Professions, 26(1), 46-54.

21. Suter, E., Deutschlander, S., \& Lait, J. (2011). Using a complex systems perspective to achieve sustainable health care practice change. Journal of Research in Interprofessional Practice and Education, 2(1), 83-99.

22. Nutbeam, D., \& Harris, E. (2004). Theory in a nutshell: A guide to health promotion theory, 2nd edition. Sydney: McGraw-Hill.

23. Gask, L., \& Khanna, T. (2011). Ways of working at the interface between primary and specialist mental healthcare. British Journal of Psychiatry, 198(1), 3-5.

24. Habermas, J. (1984a). The theory of communicative action, volume 1. Reason and the rationalization of society. Boston: Beacon Press.

25. Kubacki, S.R. (1994). Applying Habermas's theory of communicative action to values in psychotherapy. Psychotherapy: Theory, Research, Practice, Training, 31(3), 463-477.

26. Habermas, J. (1984b). The theory of communicative action, volume 2. Lifeworld and system: A critique of functionalist reason. Boston: Beacon Press.

27. Brand, A. (1990). The force of reason: An introduction to Habermas' theory of communicative action. Sydney: Allen \& Unwin. 


\section{JRIPE \\ Journal of Research in Interprofessional Practice and Education}

15

Defining Mental

Health Collaborative

Practice

Jones

\& Delany
28. Heidegger, M. (1962). Being and time. New York: Harper and Row.

29. Crotty, M. (1998). The foundations of social research: Meaning and perspective in the research process. Sydney: Allen \& Unwin.

30. Popay, J., Rogers, A., \& Williams, G. (1998). Rationale and standards for the systematic review of qualitative literature in health services research. Qualitative Health Research, 8(3), 341-351.

31. Strauss, A.L., \& Corbin, J.M. (1990). Basics of qualitative research: Grounded theory procedures and techniques. Newbury Park, CA: Sage Publications.

32. Yan, J., Gilbert, J., \& Hoffman, S.J. (2007). World Health Organization study group on interprofessional education and collaborative practice. Journal of Interprofessional Care, 21(6), 588-589.

33. Griffin, E.A. (1997). A first look at communication theory, 3rd edition. New York: McGraw-Hill.

34. Oxman, A., Bjørndal, A., Flottorp, S., Lewin, S., \& Lindahl, A. (2008). Integrated health care for people with chronic conditions. Oslo: Norwegian Knowledge Centre for the Health Services.

35. Myers, M.D., \& Young, L.W. (1997). Hidden agendas, power and managerial assumptions in information systems development: An ethnographic study. Information Technology \& People, 10(3), 224-240. 